\title{
OLIMPÍADAS MODERNAS: A HISTÓRIA DE UMA TRADIÇÃO INVENTADA
}

\author{
Mariza Antunes de Lima \\ Graduada em Educação Física pela Universidade Positivo, pesquisadora júnior do Núcleo de Pesquisa Futebol \& \\ Sociedade e professora da rede pública de ensino.
}

\section{Clóvis J. Martins}

Graduado em Educação Física pela Universidade Positivo e pesquisador júnior do Núcleo de PesquisaFutebol \& Sociedade.

\author{
André Mendes Capraro \\ Doutor em História pela Universidade Federal do Paraná, professor adjunto e coordenador do Centro de Memória \\ do Departamento de Educação Física na mesma instituição.
}

\begin{abstract}
Resumo
Esta pesquisa investiga se a origem das Olimpíadas Modernas pode ser compreendida como uma tradição inventada. Foi abordado o "ressurgimento" das Olimpíadas, uma comparação entre Jogos Helênicos Antigos (especificamente os Olímpicos) e as Olimpíadas Modernas e uma reflexão sobre os ideais e rituais inventados nas Olimpíadas da atualidade. A pesquisa baseia-se em dois autores: Eric Hobsbawm e Norbert Elias, sobretudo no que se refere ao esporte. $\mathrm{O}$ esporte como um fenômeno moderno demonstra que esse "ressurgimento" dos Jogos Olímpicos e seus novos elementos, normalmente tratados por alguns autores como uma continuidade, devem ser compreendidos como uma tradição inventada. Palavras-chave: Jogos Olímpicos Modernos - História do Esporte - Tradição Inventada
\end{abstract}

Tratando-se da Civilização Helênica, história e mito em vários momentos se fundem, ganhando certa unidade. Entretanto, na era moderna, as Olimpíadas apresentam contradições quando acentuada sua derivação dos antigos Jogos Gregos. Elias e Dunning (1992, p. 189), por exemplo, refutam a idéia disseminada por muitos historiadores, que consideram o esporte como uma continuidade ou um "renascimento" de competições atléticas que teriam existido na antiguidade.

Os referidos autores afirmam que os Jogos competitivos da Grécia clássica, normalmente identificados como o grande paradigma do esporte, apresentavam certas características próprias e se desenvolveram em condições muito distintas das que derivam os esportes atuais.

Outro ponto de vista nesse mesmo sentido foi feito por Katia Rubio ao relatar que, diferentemente da cultura helênica, na qual o período dos Jogos representava um momento de trégua nas guerras e conflitos, as Olimpíadas Modernas já sofreram interrupções por duas grandes guerras e boicotes promovidos por Estados Unidos e União Soviética na década de 1980, indicando que o movimento olímpico não é tão apolítico como se proclama (RUBIO, 2001, p. 131).

Ao referir-se aos Jogos Olímpicos, Pleket (1989 apud NETO 1998, p. 723) lembra que as diferenças entre os jogos antigos e os modernos não devem ser jamais esquecidas e que, entre essas diferenças, pode-se destacar que as competições antigas aconteciam sempre no mesmo lugar: o santuário de Olímpia, e os principais 
símbolos das Olimpíadas Modernas não têm nenhum tipo de ligação com os Jogos da Antiguidade.

A presente pesquisa apoia-se principalmente na formulação teórica de Hobsbawm e Ranger (1997), mais especificamente, no livro A Invenção das Tradiçôes. Nessa obra está descrito, em suma, que se inventam novas tradições quando ocorrem transformações que sejam ao mesmo tempo amplas e abrangentes nas sociedades modernas.

O termo "tradição inventada" é utilizado num sentido amplo, porém definido e que inclui tanto as tradições realmente inventadas quanto aquelas que surgiram de maneira mais difícil de localizar e em um período limitado e determinado de tempo. Muitas vezes práticas de poucos anos se estabelecem com grande rapidez.

Assim, Hobsbawm e Ranger (1997, p. 9) consideram uma tradição inventada por:

Um conjunto de práticas, normalmente reguladas por regras tácitas ou abertamente aceitas. Tais práticas de natureza ritual ou simbólica visam inculcar certos valores e normas de comportamento através da repetição, o que implica, automaticamente, uma continuidade em relação ao passado, aliás, sempre que possível, tenta-se estabelecer uma continuidade com um passado histórico apropriado.

Em face desta afirmação levanta-se a seguinte questão: as Olimpíadas Modernas podem ser compreendidas como uma tradição inventada?

Os Jogos Olímpicos antigos eram festivais sagrados, nos quais os atletas competiam para servir aos deuses; por outro lado, as Olimpíadas Modernas, nasceram sem vínculo religioso, idealizada por Pierre de Coubertin seguidor da teoria darwinista, e que teve início na Inglaterra logo após a Revolução Industrial, surgindo como um evento laico e sem nenhuma relação com a divindade (HELAL, 1990, p. 35).

Apesar disso, a maioria das publicações que tratam sobre o assunto repete a mesma história, normalmente preocupando-se em relatar o surgimento dos Jogos Antigos e seu ressurgimento em 1896 com Pierre de Coubertin, concebidos como Olimpíadas Modernas. Por sinal, ao referir-se aos Jogos Olímpicos antigos, histórias diversas surgem para tentar explicar sua verdadeira origem. $\mathrm{Na}$ maioria das vezes, tais narrativas se preocupam apenas em citar que as Olimpíadas Modernas aparecem como uma continuação dos antigos Jogos Gregos.

No entendimento de Godoy (1996, p. 53), não é possível precisar quando e porque os Jogos Olímpicos foram instituídos, apesar de oficialmente serem considerados como os primeiros Jogos Olímpicos da antiga Grécia, os realizados em 776 a.C. Além dos Jogos Olímpicos em homenagem a Zeus, segundo Giordani (2001, p. 259), existiam outros eventos na Grécia antiga como: Jogos Fúnebres, Píticos, Nemeus, Ístmicos, Heranos - este último destinado apenas às mulheres. Embora seja ressaltado que os mais consagrados tenham sido mesmo os Olímpicos.

Sobre o surgimento dos Jogos Olímpicos na antiguidade, Neto (1998, p. 721) aponta algumas vertentes acadêmicas: Lee (1988) relata que, de acordo com as evi- 
dências arqueológicas, é possível que tenham existido 27 jogos antes de 776 a.C., os quais não tinham grande significado. Já Mallwitz (1988), diretor alemão das escavações em Olímpia, acredita que os Jogos tiveram início no ano de 704 a.C. e eram realizados anualmente, sendo que somente em 680 a.C., passaram a ser quadrienais. Por último, Wacker (1996) acredita que a data de 776 a.C. deve ser um falso fato histórico criado na cidade de Elis, por uma série de razões. Ele argumenta que as descobertas realizadas pelos arqueólogos demonstraram que o santuário de Olímpia foi aumentado por volta de 700 a.C. e que não existiam evidências da existência de atividades competitivas antes desse período.

Além dessas, existem várias outras formulações históricas sobre o surgimento dos Jogos Olímpicos. Boga (1991, p. 26) afirma que na antiguidade os jogos foram creditados a Heracles ou (Hércules) que, para prestar uma homenagem ao rei Augias, morto em combate durante a conquista da cidade de Elis, instituiu em sua memória competições atléticas que vieram a se chamar Jogos Herácleos.

Uma outra versão é a de Fernandes (1980, p. 76), pautada em uma história mítica:

Pélope, avô de Héracles, apaixonou-se pela filha de Enómao, rei de Pisa, que de acordo com o oráculo seria morto pelas mãos do próprio genro. Este fato fez com que Enómao se opusesse ao casamento da filha Hipodamia. Porém, para satisfazer o desejo dos pretendentes, concordou em realizar uma prova de corridas de carros, durante a qual ele tentava acertar os concorrentes com uma lança. Um a um os pretendentes foram caindo mortos, exceto Pélope que havia subornado o cocheiro real, para que sabotasse o carro de rei, provocando um acidente que veio resultar em sua morte. Como forma de agradecimento à vitória conquistada Pélope organizou os Jogos.

$\mathrm{Na}$ verdade, não existem registros exatos sobre a origem dos Jogos Olímpicos antigos, mas sim, diferentes hipóteses sobre sua criação. Reforçando tal idéia, Neto (1998, p. 721) acentua que a origem dos jogos antigos se perde no tempo e que não existe nenhum tipo de certeza em relação à data de início dos jogos e a razão para sua criação.

Guttmann (2001) acredita que é um equívoco a tendência de se considerar as práticas gregas como antecessoras dos esportes modernos. Para o sociólogo, a conformação dessas práticas está muito mais próxima das atividades dos povos primitivos que das Olimpíadas da modernidade. Nos jogos gregos o caráter religioso nunca ficou em dúvida (GUTTMANN; THOMPSON, 2001, p. 3).

Guttmann (1978) ainda estabelece algumas características típicas do esporte moderno: secularidade, igualdade, especialização, racionalização, burocracia, quantificação e busca pela quebra de recordes. Tais características não são encontradas nos “esportes primitivos" (GUTTMANN, 1978, p. 16).

A secularização consiste na não vinculação do esporte com o terreno sagrado. Como entende Guttmann (1978, p. 17), “[...] o esporte é um fenômeno secular, o tempo do esporte não é mais um tempo ritual”. Essa secularização pode ser vista como uma diferença entre os antigos Jogos Gregos e as Olimpíadas Modernas.

A segunda característica dos esportes modernos, apontada por Guttmann (1978), é a igualdade. $\mathrm{O}$ esporte solicita, pelo menos teoricamente, que todos sejam admitidos por suas habilidades atléticas e que a regra seja igual para todos os competidores. Entretanto Guttmann (1978) não esclarece totalmente as transformações que constantemente ocorrem em se tratando das regras. 
Sobre esse aspecto pode-se buscar amparo nos escritos de Elias e Dunning (1996), quando se referem à caça à raposa, um dos primeiros passatempos com características distintivas de desporto, mesmo que na atualidade a caça seja considerada por muitos como uma forma marginal de competição esportiva (sujeita às formas mais adversas de manifestações contrárias da parte dos ambientalistas). No século XVIII e início do século XIX, a caça à raposa foi decididamente um dos principais passatempos a que o termo desporto foi aplicado (ELIAS e DUNNING, 1992, p. 236).

A especialização aparece como a terceira característica do esporte moderno. Guttmann (1978, p. 28) sustenta que nos povos primitivos as regras não eram bem definidas e esclarece:

Estes 'Jogos', se referindo aos Jogos antigos, eram semelhantes em três aspectos: várias modalidades eram contidas frequentemente em um único jogo, havia uma pequena divisão de trabalho entre os jogadores e normalmente não havia distinção entre jogar e assistir.

Mais uma grande diferença, nas Olimpíadas Modernas os esportes são exatamente o oposto à referência supracitada, e esta especialização pode ser entendida como o que hoje é conhecido por profissionalismo (Proni, 2004).

A racionalização se apresenta como a adoção de regras específicas e o uso de equipamentos tecnológicos. Para o Guttmann, as regras sempre existiram, o que mudou foi a natureza das regras, ou seja, deixaram de ser "instruções divinas". Um exemplo citado por Guttmann $(1978$, p. 40) foi a própria caça. Ela era detentora de um caráter utilitário e desigual, sendo racionalizada, transformou-se em uma modalidade esportiva moderna, o tiro ao alvo ou o tiro com arco.

A burocratização trata da organização institucional que estabelece e decide as regras e fiscaliza os jogos. Já a quantificação representa nos esportes modernos a vida cotidiana, um mundo de números que é extremamente enfatizado e mensurável no esporte moderno - como, por exemplo, as estatísticas exibidas nas partidas de futebol (chutes a gol, número de faltas, escanteios, tempo e percentual de posse de bola, etc.).

E finalmente a busca pela quebra de recordes refere-se à superação do superado. Como cita Gontijo (2004, p. 51), a história da escrita é recente e estimula uma consciência de diferença entre passado e presente, e, embora não existam evidências de que a escrita foi criada apenas para enviar mensagens, tudo leva a crer que a intenção de registrar está associada à necessidade de lembrar, diferente das culturas orais que tendem a esquecer o passado. Neste sentido, a característica de registrar é encontrada somente nos esportes modernos.

Mesmo não aceitando tais características como verdade absoluta e reconhecendo que existem limitações na classificação proposta por Guttmann (1978), acredita-se que elas servem como parâmetro para distinguir as diferenças entre os antigos Jogos Gregos e as Olimpíadas Modernas.

Reforçando essa idéia, Simonovic (2004) afirma que Coubertin usou o termo Jogos Olímpicos, não porque foi inspirado pela herança espiritual antiga, mas porque o tema apresentava um "caráter solênico", onde viu uma denotação peculiar para as competições esportivas internacionais e planejava organizá-las e institucionalizá-las e continua: "Coubertin não tentou renovar os antigos Jogos Olímpicos para desenvol- 
ver o esporte, mas sim colaborar com o desenvolvimento da força nacional da França e sua expansão colonial" (SIMONOVIC, 2004).

Assim, atento às distinções, no que se refere aos Jogos Olímpicos antigos e seu surgimento, principalmente quando existe a tentativa de relacioná-los com as Olimpíadas Modernas, tal continuidade histórica torna-se infundada.

\section{III}

Tendo em vista as colocações e as diferenças apresentadas em relação aos Jogos Olímpicos antigos quando comparados aos Modernos, Hobsbawm e Ranger (1997, p. 10) argumentam:

$\mathrm{Na}$ medida em que há referência a um passado histórico as tradições inventadas caracterizam por estabelecer com ele uma continuidade bastante artificial. Em outras palavras, elas são reações a situações novas, que assumem a forma de referência a situações anteriores ou estabelecem seu próprio passado através da repetição, quase que obrigatória.

Segundo Proni (2004, p. 1) as Olimpíadas Modernas, desde que foram concebidas em 1896, cresceram e ganharam símbolos e rituais próprios, tornando-se um evento singular no calendário esportivo mundial. Entretanto, é importante destacar que esses símbolos nada tinham a ver com os antigos Jogos gregos.

Tais símbolos são considerados parte significativa de uma tradição, logo, são passíveis de mudanças. Para Hobsbawm e Ranger (1997, p. 10), as tradições devem ser, neste sentido, nitidamente diferenciadas dos "costumes" vigentes nas sociedades ditas "tradicionais". Os objetivos e as características das tradições, inclusive das inventadas, é a invariabilidade. O passado real ou forjado a que se referem impõem práticas fixas, tais como a repetição. A característica de repetição foi utilizada por Coubertin ao tentar acentuar no final do século XIX que as Olimpíadas Modernas se tratavam do mesmo evento que aconteceu na antiguidade grega.

Além disso, as tradições podem evoluir ao longo do tempo ou se transformar de modo repentino. Dessa maneira, as tradições são inventadas e reinventadas o tempo todo - diferentemente dos costumes, que passam de geração a geração. Exemplificando a idéia, Hobsbawm e Ranger (1997, p. 11) comentam que o costume não impede as inovações e pode mudar até certo ponto, embora deva sempre parecer compatível ou idêntico ao seu precedente.

Para Hobsbawm e Ranger "costume é o que fazem os juízes, tradição (no caso a inventada) é a peruca, a toga e os outros acessórios e rituais formais que cercam a substância, que é a ação do magistrado, ou seja, a decadência do costume inevitavelmente modifica a tradição" (HOBSBAWM e RANGER, 1997, p. 10).

Assim, Hobsbawm e Ranger (1997, p. 19) prosseguem:

Pode-se observar uma nítida diferença entre as práticas antigas e as inventadas. As primeiras eram práticas sociais específicas e altamente coercivas, enquanto as últimas tendiam a ser bastante gerais e vagas quanto à natureza dos valores, direitos e obrigações que procuravam inculcar nos membros de um determinado grupo: "patriotismo", "lealdade", "dever", "as regras do jogo", "o espírito escolar", e assim por diante. 
Os referidos símbolos apresentam-se aqui como tradições inventadas acerca dos jogos, como exemplos surgem: os anéis, a bandeira, o lema, a chama e o hino.

Os cinco anéis representam os cincos continentes, embora não haja uma especificação de cada anel para um determinado continente. Eles são entrelaçados para mostrar a universalidade do olimpismo e do encontro de atletas do mundo todo durante as Olimpíadas. A forma como os anéis foram entrelaçados inicialmente é estranha se comparada à forma atualmente conhecida. Eles apareceram pela primeira vez no topo de uma carta escrita por Pierre de Coubertin em 1913 (LENNARTZ, 2001/2002).

Também foi Coubertin que projetou a bandeira olímpica e a apresentou em junho de 1914, em Paris, onde, os anéis apareciam num fundo branco. A bandeira reforça a universalidade do movimento olímpico, como se trouxesse consigo todos os países do mundo. Coubertin, “o pai das Olimpíadas Modernas”, explica o significado:

A Bandeira Olímpica [...] tem um fundo branco, com cinco anéis entrelaçados no centro: azul, amarelo, preto, verde e vermelho [...]. Este design é simbólico, ele representa os cinco continentes do mundo, unidos pelo Olimpismo, enquanto as seis cores são aquelas que aparecem em todas as bandeiras nacionais do mundo no momento. (LENNARTZ, 2001/2002, p. 470).

Pierre de Coubertin foi quem adotou de seu amigo Henri Didon, um padre dominicano que ensinava esportes para estudantes, três palavras de origem latina: Citius, Altius, Fortius, que significam, respectivamente, o mais rápido, o mais alto e o mais forte. Estas três palavras encorajavam o atleta a dar o seu melhor durante a competição e ver seu esforço como uma vitória. Esse lema resume-se como uma filosofia de vida, ou um código de conduta a ser seguido e foi apresentado no mesmo ano da criação do Comitê Olímpico Internacional, em 1894 (LENNARTZ, 2001/2002).

A tocha olímpica também aparece como símbolo das Olimpíadas Modernas e foi apresentada pela primeira vez em 1936, nos Jogos de Berlim. Muito embora seja afirmado que sua gênese foi na Grécia antiga, ela não fazia parte dos Jogos Antigos (LENNARTZ, 2001/2002).

O hino olímpico também surgiu como um símbolo esportivo. Foi composto por Spiros Sâmara, baseado nas palavras de Kosta Palama, para a primeira Olimpíada ocorrida na Era Contemporânea, no ano de 1896. O hino foi tocado novamente em 1906 e substituído por um outro especialmente preparado para as cerimônias olímpicas. Em 1954, o Comitê Olímpico Internacional (COI) organizou um concurso internacional que foi vencido pelo compositor polonês Michael Spisiak, o qual utilizou um poema de Pindaro para a música. Foi tocado nos Jogos de Melbourne em 1956, mas o compositor exigiu uma taxa abusiva e esse hino foi deixado de lado. Quando os japoneses tocaram a canção de Spiros Samara na 55a Sessão do COI em 1958, em Tókio, todos, levados pela beleza da canção, a escolheram unanimemente, sendo adotado como hino oficial. Assim, foi apresentado ao público em 1960, na Olimpíada sediada em Roma (LENNARTZ, 2001/2002).

Outra tradição seria a antiga frase "O importante não é vencer, mas sim participar”, creditada na maioria das vezes ao próprio Pierre de Coubertin, mas sendo proferida pela primeira vez em 1908 pelo bispo da Pensilvânia durante um sermão aos atletas que disputariam as Olimpíadas de Londres(LENNARTZ, 2001/2002). 
Apresenta-se ainda, nas Olimpíadas Modernas, a fabricação de outras tradições, vinculadas ao próprio termo "Jogos Olímpicos". Pois é possível vislumbrar que esse "nome fantasia" traz consigo outras tradições: a história dos antigos Jogos Gregos, o acender da pira, a paz olímpica - símbolos que tentam demonstrar uma ligação com um passado distante.

Assim como os símbolos citados acima não faziam parte desse passado, ora remoto, ora recente, também apareceram outros no decorrer da história, que serão apontados aqui como as novas tradições inventadas. Destacam-se: o percurso mundial da tocha olímpica, os mascotes, a escolha das cidades-sedes e os cartazes oficiais.

Sobre o percurso da tocha olímpica, no entendimento de Rolim, Mazo e Todt (2006, p. 707), "a corrida de revezamento da Tocha Olímpica é uma tradição inventada, que foi constituída com base em idéias nacionalistas para a abertura da Olimpíada de Berlim em 1936”, sendo apenas nas Olimpíadas de Atenas (2004) que a tocha olímpica efetivamente percorreu todos os continentes, passando inclusive pelo Brasil.

Ainda no âmbito das tradições inventadas, surgem novas alegorias que tentam cativar o público. Sobre os mascotes olímpicos, Silvino (2004) explica que "a palavra mascote surgiu em 1860 e vem do provençal 'masco', que significa mágico (...)”, atualmente as mascotes fazem parte do conjunto de merchandising das Olimpíadas.

O primeiro mascote oficial surgiu em 1972, em decorrência do sucesso de Schuss (Mascote não oficial da Olimpíada de Inverno de Genebra em 1968), o escolhido pelos anfitriões alemães foi o cãozinho da raça basset chamado de Waldi. Devido à favorável resposta do público, a partir de então todas as Olimpíadas têm adotado seus mascotes oficiais: Amik em Montreal, o urso Misha em Moscou, a águia Sam em Los Angeles, o tigre Hodori em Seul, o cãozinho Cobi em Barcelona, o Izzy em Atlanta, Ollie, Syd e Millie em Sidney, Phevos e Athena em Atenas e em Pequim Beibei, Jingjing, Huanhuan, Yingying e Nini (SILVINO, 2004).

Outro fato que gera expectativas é a escolha das cidades-sedes. Algumas cidades se candidatam e passam por uma rigorosa seleção. Uma delas é escolhida e apresentada ao público pelo COI. Normalmente a cidade escolhida é informada oito anos antes da realização da Olimpíada. Entretanto, a organização deste megaevento demanda um envolvimento direto do poder público e também de iniciativas privadas. Para Rubio (2005, p. 7):

\footnotetext{
No início do século XX, o poder público era inteiramente responsável pela candidatura e realização do evento. No presente, desde o momento em que a cidade se candidata e apresenta seu projeto ela necessita criar uma infra-estrutura para viabilizar, no princípio, uma idéia (de que a cidade é viável para acolher um megaevento), em seguida, afirmar sua especificidade (que a faz diferente e melhor das demais concorrentes) e, por fim, viabilizar sua capacidade (momento em que são feitas as adequações necessárias para receber o evento em si e todo o universo que gravita no seu entorno).
}

Se no final do século XIX, apenas Atenas se apresentava disposta a sediar as Olimpíadas, no decorrer do século XX, as disputas entre as cidades candidatas a sediar as Olimpíadas tornaram-se cada vez mais acirradas. Para o processo de seleção entre as cidades são avaliados critérios como: as instalações poliesportivas existentes e sua adaptação; criação de um novo projeto olímpico; repasse das instalações para a população; apoio da população civil; estrutura de turismo e de lazer; 
sistema de transporte; facilidade de telecomunicações; segurança; deslocamentos; alinhamento do projeto urbano com o projeto olímpico; entre outros (BITTENCOURT, 1999, p. 81).

Os cartazes oficiais para a divulgação das Olimpíadas também fazem parte de mais uma tradição da era Moderna. Com exceção dos anos de 1916, 1940 e 1944, pois a realização das Olimpíadas foi cancelada em virtude das duas Grandes Guerras, todas as outras tiveram a confecção de cartazes oficiais.

Em uma análise feita pela pesquisadora Lima (2004), sobre os cartazes é destacado que estes se utilizam de símbolos que normalmente são usados mais de uma vez, como a figura humana, os elementos relacionados ao país sede, ou a imagem do atleta em ação. O excesso de informação nos primeiros cartazes também foi destacado na análise, assim como uma mudança radical a partir da Olimpíada de 1928 em Amsterdã, que publicou um cartaz simples e informativo. Outros pontos destacados foram o da figura feminina (que aparece somente nos dois primeiros cartazes) e os anéis - o principal símbolo olímpico criado por Pierre de Coubertin em 1914 só foi utilizado a partir de 1932.

Ainda existem outras tradições recentes que nasceram a partir do desenvolvimento das Olimpíadas Modernas, como as vilas olímpicas, que surgiu em Berlim em 1936; as medalhas, que foram instituídas em 1904 nos Jogos de Saint Louis; o Museu Olímpico inaugurado em 1993, pelo então presidente do COI Juan Antônio Samaranch, na Suíça; e os selos comemorativos em 1896, que vieram para auxiliar a complementação das verbas, pois $50 \%$ da renda obtida foi para a organização das Olimpíadas (PAHUD, 2002).

A descrição desses símbolos "tradicionais" é exemplificada pelos historiadores referidos anteriormente. Hobsbawm e Ranger (1997) dão exemplos de tradições inventadas em vários países e descrevem que a “invenção das tradições” é essencialmente um processo de formalização e ritualização, caracterizado por se referir ao passado, mesmo que apenas pela imposição da repetição. Pode-se entender, portanto, que as tradições são fabricadas, ao invés de se desenvolverem espontaneamente, ou seja, não existiram desde tempos remotos (HOBSBAWM e RANGER, 1997, p. 12).

Partindo dessa premissa, entende-se que todos os símbolos associados às Olimpíadas Modernas fazem parte de um conjunto de tradições inventadas e estas tendem a persistir. Assim, é possível afirmar que houve uma espécie de equilíbrio entre modernidade e tradição, considerando que as sociedades ditas "tradicionais" mantêm elementos como a família, a religião, a língua e o trabalho.

Nesse sentido, essa ascensão retrata uma proposital exaltação da antiguidade numa alusão de continuidade acerca dos antigos jogos. Por outro lado, o seu declínio favoreceu o esquecimento dos rituais sagrados, substituídos por rituais pomposos e espetacularizados, como os observados nas Olimpíadas Modernas.

Em concordância, já escreveram Allen Guttmann (1978), Norbert Elias (1992) e Eric Hobsbawm (1997), entre outros autores, que o esporte é moderno. Ainda que Guttmann (1978) fale de racionalização e burocratização, Elias (1992) destaque o controle da violência e o processo de civilização ou ainda que Hobsbawm(1997) se 
refira à formação do esporte como um instrumento como tantos outros, utilizado para inculcar valores e normas de comportamento através da repetição, todos concordam que o esporte como é conhecido hoje apresenta sua origem na Inglaterra no decorrer dos séculos XVIII e XIX.

Deve-se, entretanto, frisar que a Olimpíada Moderna é um fenômeno em construção. Neste sentido, existem alguns elementos que influenciaram a compreensão em geral da sua verdadeira origem. A maioria das referências bibliográficas sobre a história das Olimpíadas, por exemplo, apresenta contradições, pois primeiro os autores tratam do "ressurgimento" dos Jogos Olímpicos, para, logo em seguida, relatar que Coubertin buscou "inspiração" para seu projeto esportivo na Grécia antiga e no modelo educativo das escolas públicas inglesas. Brigatti (1994, p. 41) descreve que, alheios à essência religiosa, os Jogos Olímpicos "ressurgem" com uma filosofia pautada na obediência incondicional às normas de cada esporte, ou seja, à civilidade européia.

Em síntese, a partir de autores como Hobsbawm (1997), Elias e Dunning (1992) e Guttmann (1978), é possível afirmar categoricamente que os jogos gregos tinham características bem específicas: eram manifestações populares e religiosas para homenagear os deuses, realizados sempre no mesmo lugar, no santuário de Olímpia, tendo como objetivo principal vencer para agradar às divindades. Em contrapartida, ainda de acordo com os referidos autores, as Olimpíadas Modernas contemplam apenas o esporte: práticas competitivas com regras pré-estabelecidas, sem nenhum vínculo religioso, apresentando como uma de suas principais características o rendimento. Sem contar outra diferença fundamental: o nível de violência, que nos esportes modernos é sensivelmente mais tênue do que nos jogos gregos (Elias; Dunning, 1992).

Portanto, partindo da compreensão do esporte como um fenômeno moderno, ressalta-se que esse "ressurgimento dos Jogos Olímpicos e seus novos elementos", tratados por alguns autores como continuidade, podem ser compreendidos aqui como uma tradição inventada.

\title{
Modern olympics: the history of an invented tradition
}

\begin{abstract}
This research work investigates whether the origin of the Modern Olympics can be understood as an invented tradition. It approaches the "resurgence" of the Olympics by comparing the ancient Helenic Games (and, more specifically, the ancient Olympic Games) to the Modern Olympics. It then reflects on the ideals and rituals invented for the Modern Olympics. Eric Hobsbawn's and Norbert Elias' works serve as references, especially with regards to sports, which, as a modern phenomenon, is evidence that the resurgence of the Olympic Games and its new elements, normally treated by a few authors as a continuity, are actually to be understood as an invented tradition.
\end{abstract}

Keywords: Modern Olympic Games - Sport History - Invented Tradition

\section{Juegos olímpicos modernos: historia de una tradición inventada}

\section{Resumen}

Con una revisión bibliográfica, se investiga en este estudio si el origen del Olimpíadas Modernas se puede entender como una tradición inventada. Fue abarcado el "resurgimiento" de las Olimpíadas, una comparación entre los viejos juegos griegos (específicamente el Olímpicos) y las Olimpíadas modernas, además de una reflexión sobre los ideales y los rituales creados en el Olimpíadas actuales. La investigación se basa, en dos autores: Eric Hobsbawm y Norbert Elias, principalmente cuanto al deporte. El 
deporte como fenómeno moderno demuestra que este "resurgimiento" de los juegos de Olímpicos y de sus nuevos elementos, tratado normalmente por algunos autores como una continuidad, debe entenderse como una tradición inventada.

Palabras-clave: Juegos Olimpicos Modernos - Historia de los deportes - Tradición inventada

\section{Referências}

BITTENCOURT, A. C. Cidades candidatas versus cidades olímpicas: o processo de eleição, o sucesso, o fracasso, a modelagem e os conceitos de real valor. In: TAVARES O.; COSTA, L. P. (orgs). Estudos olimpicos. Rio de Janeiro: Gama Filho, 1999, p. 32.

BOGA, M. Educaşão física e sociedade. São Paulo: Movimento, 1991.

BRIGATTI, M. E. O Termo esporte: perspectivas históricas. In: II ENCONTRO NACIONAL DE HISTÓRIA DO ESPORTE, LAZER E EDUCAÇÃO FÍSICA. 1994, DEF/UEPG. Anais do II Encontro Nacional de História do Esporte, Lazer e Educação Física. DEF/UEPG: Editora da FEF/UNICAMP, 14 de Outubro de 1994, p. 232.

ELIAS, N.; DUNNING, E. A Busca da excitação. Lisboa: Difel, 1992.

FERNANDES, R. Jogos olimpicos: citius, altius, fortius. São Paulo: Porto, 1980.

GIORDANI, M. C. História da Grécia. 7ed., Petrópolis: Vozes, 2001.

GODOY, L. Os Jogos olímpicos na Grécia antiga. São Paulo: Nova Alexandria Ltda, 1996.

GONTIJO, S. O Livro de ouro da comunicação. Rio de Janeiro: Ediouro, 2004.

GUTTMANN, A. From ritual to record: the nature of modern sports. New York: Columbia University, 1978.

GUTTMANN, A.; THOMPSON, L. B. Japanese sports: a history. Hawaii: University of Hawaii, 2001.

HELAL, Ronaldo. O que é sociologia do esporte. São Paulo: Brasiliense,1990.

HOBSBAWM, E.; RANGER, T. A Invenção das tradiçôes. 2ed., São Paulo: Paz e Terra S.A, 1997.

LEE, H. Some changes in the ancient olympic program and the ancient olympic program and schedule. In COULSON, W.; KYRIELEIS, H. (ed). Proceeding of an international symposium on the olympic games. 5/9 september, Atenas, Deutsches Archaologisches Institut Athen, 1988.

LENNARTZ, K. The Story of the Rings. The Journal of Olympic History. v. 10. Dec. 2001/Jan. 2002.

LIMA, E. L. C. Departamento de artes e design - análise gráfica. PUC - Rio, 2004. Disponível em: http://wwwusers.rdc.puc-rio.br/ednacunhalima/2004_1_2/olimpiadas. Acesso em 11 jun. 2007. 
MALLWITZ, A. Cult and copetition location at olympia. In RASCHKE, W. (ed). The archaeology of the olympics. Wisconsic, the University of Wisconsin Press, 1988.

NETO, M. F. Os Jogos olímpicos da antiguidade grega: mitos e realidades. In: VI CONGRESSO BRASILEIRO DE HISTORIA DO ESPORTE, LAZER E EDUCAÇÃO FÍSICA. Universidade Gama Filho, 1998. Anais... Rio de Janeiro: Universidade Gama Filho, 12 de Dezembro de 1998, s/p.

PAHUD, J.F. O Museu olímpico. In: FILHO, M. G. B.; SILVA, M. C. P.; DA COSTA, L.P. (orgs). Numismática, flatelia e memória olimpica. Rio de Janeiro: Gama Filho, 2002.

PRONI, M.W. Unicamp. A Metamorfose dos jogos olímpicos (1896 - 1996). In: XVII ENCONTRO REGIONAL DE HISTÓRIA - O lugar da História. ANPUH/SP- UNICAMP, 2004, Campinas. Anais ... Campinas: Unicamp, 10 de Setembro de 2004, s/p.

ROLIM, L. H. MAZO, J.Z. e TODT, N. Representações da tocha olímpica em Porto Alegre (1938-1945). In: MORAGAS, M e DACOSTA, L.(orgs). Universidade e Estudos Olimpicos: Seminários España - Brasil. Rio de Janeiro, 2006.

RUBIO, K. Os Jogos olímpicos e a transformação das cidades: os custos sociais de um megaevento. Scripta Nova. Revista electrónica de geografía y ciencias sociales. Barcelona: Universidad de Barcelona, v. IX, n. 194 (85), 1 ag. 2005. Disponível em: http://www.ub.es/geocrit/sn/sn-194-85.htm [ISSN: 1138-9788]. Acesso em: 12 abr. de 2007.

RUBIO, K. O Atleta e o mito do herói. 2ed., São Paulo: Casa do Psicólogo, 2001.

SILVINO, L. As mascotes olimpicas. Duplipensar, 2007. Disponível em http:// www.duplipensar.net/dossies/2004-Q3/olimpiadas-mascotes.html. Publicado em 17.08.2004. Acesso em 11 junho, 2007.

SIMONOVIC, L. Philosophy of lympism. Strucna Knjiga, 2004. Disponível em http://www.cirqueminime.blogcollective.com/blog/_archives/2006/5/22/1977075. html\#post_comment. Acesso em 19 julho 2007.

WACKER, C. Das Gymnasion in olympia - Geschichte und Funktion. Würzburg, Ergon, 1996.

Recebido em: 02 de abril de 2009

Revisado em: 24 de abril de 2009

Aprovado em: 30 de abril de 2009

Endereço para correspondência

andrecapraro@onda.com.br. 